\title{
The effect of dispersoids on the grain refinement mechanisms during deformation of aluminium alloys to ultra-high strains
}

\author{
P.J. Apps, M. Berta, P.B. Prangnell * \\ Manchester Materials Science Centre, University of Manchester/UMIST, Grosvenor Street, Manchester M1 7HS, UK
}

Received 8 April 2004; received in revised form 19 August 2004; accepted 25 September 2004

\begin{abstract}
The effect of fine dispersoids on the mechanisms and rate of grain refinement has been investigated during the severe deformation of a model aluminium alloy. A binary $\mathrm{Al}-0.2 \mathrm{Sc}$ alloy, containing coherent $\mathrm{Al}_{3} \mathrm{Sc}$ dispersoids, of $\sim 20 \mathrm{~nm}$ in diameter and $\sim 100 \mathrm{~nm}$ spacing, has been deformed by equal channel angular extrusion to an effective strain of ten. The resulting deformation structures were quantitatively analysed using high-resolution electron backscattered diffraction orientation mapping, and the results have been compared to those obtained from a single-phase Al-0.13Mg alloy, deformed under identical conditions. The presence of fine, nonshearable, dispersoids has been found to homogenise slip, retard the formation of a cellular substructure and inhibit the formation of microshear bands during deformation. These factors combine to reduce the rate of high-angle grain boundary generation at low to medium strains and, hence, retard the formation of a submicron grain structure to higher strains during severe deformation. (C) 2004 Acta Materialia Inc. Published by Elsevier Ltd. All rights reserved.
\end{abstract}

Keywords: Severe deformation; Ultra-fine grains; Grain subdivision; Microshear bands; Fine particles; Dispersoids; $\mathrm{Al}_{3} \mathrm{Sc}$

\section{Introduction}

The potential benefits of submicron-grained aluminium alloys, such as enhanced strength and superplasticity, are well documented [1,2]. The last decade has witnessed considerable research interest in the use of high-strain deformation techniques to produce ultra fine-grained materials at a low cost. Several processing methods have been shown to be effective for their production, including equal channel angular extrusion (ECAE) and accumulative roll bonding (ARB) [3-5]. However, gaps still exist in the understanding of the grain refinement mechanisms operating during severe deformation processing. In particular, the effects of important microstructural variables associated with the initial material, such as the role of small dispersoid par\footnotetext{
3586 .

* Corresponding author. Tel.: +44 161200 2610; fax: +44 161200

E-mail address: philip.prangnell@umist.ac.uk (P.B. Prangnell).
}

ticles, have still to be addressed. This is an important consideration, as the requirement of thermal stability in ultra-fine grained materials will frequently necessitate the use of fine dispersoid particles to inhibit grain growth. Indeed, to obtain high strain-rate superplastic properties, alloys containing large densities of fine dispersoid particles have frequently been processed by severe deformation techniques [6].

\subsection{Deformation of single-phase Al-alloys}

A reasonably well-accepted model now exists describing the development of deformation structures in dilute single-phase Al-alloys deformed to conventional strain levels $(\varepsilon \sim 3)$ by processes such as rolling. This model is supported by extensive TEM studies carried out by the Risø research group (e.g., [7-10]) and, more recently, by detailed electron backscattered diffraction (EBSD) studies carried out by Hurley and Humphreys [11,12]. In previous work by the current authors this model 
has been extended into the ultra-high strain range found during severe deformation processing [13-16] and is briefly described below before reviewing the potential effects of dispersiod particles. At relatively low strains $(\varepsilon>\sim 0.2)$ a regular aligned cellular structure is formed by recovery of trapped glide dislocations. As the strain is increased the cell boundaries become well defined and, in the model proposed by the Risø group, the cell structure is subdivided into elongated 'cell-blocks', separated by dense dislocation walls (DDWs), designating regions operating on 2-3 slip systems, which collectively deform to accommodate the Taylor criterion for a given grain. Recent EBSD analysis by Hurly and Humphreys has suggested that these structures may be described more simply as cell bands aligned $\sim 35^{\circ}$ to the rolling direction [11,12]. At low strains the boundaries of the cell bands are transient features as they maintain this orientation with strain. The cell bands generally have alternating relative misorientations of $\sim 5^{\circ}$, which do not increase significantly with strain and contain incidental dislocation cell walls with very low misorientations $\left(<3^{\circ}\right)[11]$. At strains of $\varepsilon>0.5$, localised shear occurs in microshear bands which cut the aligned cell bands at $\sim 5-10 \mu \mathrm{m}$ intervals [11]. The microshear band boundaries rapidly increase in misorientation from $\sim 5^{\circ}$ at a strain of $\sim 1.4$, to as high as $50^{\circ}$ at a strain of $\sim 2.3$. As the strain increases some of the cell block, or cell band boundaries also evolve to form higher misorientation boundaries, which along with the microshear band boundaries become persistent and undergo a rigid body rotation towards the deformation direction as the strain increases to form a lamellar structure.

This model is consistent with previous observations of Bowen and Prangnell, who investigated the grain refinement mechanisms during severe deformation behaviour of the same single-phase alloy $(\mathrm{Al}-0.13 \mathrm{Mg}$ ) as Hurley and Humphreys [11,12] during equal channel angular extrusion to a strain of $\varepsilon_{\mathrm{vm}} \sim 10$ [14-17]. They suggested that the large increase in high-angle grain boundary (HAGB) fraction produced during severe deformation originates from the extension of grain boundaries present prior to deformation and new boundaries formed by subdivision process, such as at coarse granular-scale deformation bands and from microband boundaries that disrupt the cell block structure (referred to in the following text as 'microshear bands', to be consistent with the terminology of Hurley and Humphreys [11]). New high-angle grain boundaries were not found to form via a gradual increase in misorientation of low-angle subgrain boundaries, which did not increase greatly above $5^{\circ}$, even at a very high strains [15-17]. At low to medium strains, they found that the majority of new HAGBs originated from microshear bands which had medium misorientations, and that these rotated with strain to form a lamellar structure by a strain of $\sim 4$. As the strain was increased, the spac- ing of the lamellar boundaries reduced until it converged with the subgrain size forming thin ribbon grains, by a strain of $\sim 5-6$. At higher strains the microstructure refined further by the progressive break-up of the ribbon grains into lower aspect ratio submicron grains. Submicron grains first formed inhomogeneously and started to develop locally at strains as low as $\varepsilon_{\mathrm{vm}} \sim 4$ [15-17], due to the intersection of microshear bands and in other regions of local intense lattice rotations. Break-up within the lamellar structure occurred due to heterogeneities in the plastic flow, caused by locally hard and soft texture components [18], or by shear bands. More recently, it has also been suggested that in such dilute Al-alloys an element of geometric dynamic recrystallisation may also be involved at these extreme strain levels [19].

\subsection{Deformation of particle-containing alloys}

The presence of second phase particles could potentially have a significant effect on many of the processes outlined above. For example, it is well known that coarse micron-scale, second-phase particles can increase the rate of dislocation generation, and develop local deformation zones containing large local misorientation gradients [20-22]. This can lead to an increased rate in the generation of HAGB area with strain so that a submicron grain structure can be obtained at a considerably lower strain than in a single-phase alloy $[23,24]$. In comparison, most research into the influence of fine dispersoid particles has focused on low strain deformation, and their effect on the rate of grain refinement through the generation of new HAGB area is not well documented. In this context, fine dispersoids are defined as particles that are too small to trap dislocation loops and develop deformation zones with significant local lattice rotations, i.e., less than $100 \mathrm{~nm}$ in diameter [25].

During low strain deformation fine dispersoid particles are known to increase the rate of dislocation generation by encouraging the formation of Orowan and prismatic loops [25-27]. This will increase the work hardening rate and dislocation density $[25,28]$, but does not necessarily mean there will be a higher rate of grain refinement, which is more dependent on heterogonous features of crystal plasticity. Barlow et al. have reported an accelerated grain refinement effect, in pure aluminium containing large dispersoids of alumina platelets ( $\sim 10 \mathrm{~nm}$ thick by $\sim 50-100 \mathrm{~nm}$ in diameter), and attributed this to enhanced dislocation generation and a reduction in the slip distances [29]. Non-deformable particles will tend to homogenise slip, whereas particles that become sheared will result in shear localisation [30]. Disperosid particles will also inhibit recovery and boundary mobility [31]. Research carried out into the influence of fine dispersoid particles by TEM investigations at conventional rolling strains in $\mathrm{Cu}$ and $\mathrm{Al}$ have shown that when the dispersoids are very finely spaced $(\sim 0.1 \mu \mathrm{m})$ 
the cell boundaries become more diffuse and well-defined cellular structures do not form until larger strains [32-34], due to the inhibition of recovery. Finely distributed dispersoids can also reduce the cell size relative to the matrix alloy, to the level of their inter-particle spacing [35], and can result in lower cell boundary misorientations [31,32]. Low volume fractions of fine disperoids are not thought to greatly influence the formation of coarse granular scale deformation bands [36], but may reduce inter-granular orientation gradients due to their homgenisation effect on slip [31]. They may also have subtle effects on the texture evolution $[37,38]$.

In order to explore further the role of disproids during severe deformation, in this investigation the deformation structure development in a model binary Al-0.2Sc alloy, containing a uniform fine dispersion of coherent $20 \mathrm{~nm}$ $\mathrm{Al}_{3} \mathrm{Sc}$ particles, has been compared to previous work and new data generated from a single-phase Al- $0.13 \mathrm{Mg}$ alloy, previously studied by Prangnell and Bowen [1517] and Hurley and Humphreys [11,12]. Both materials were deformed under identical conditions by ECAE to an effective strain of $\sim 10$. Their microstructural evolution has been quantitatively analysed, as a function of strain, using high-resolution EBSD and TEM.

\section{Experimental}

A high-purity $\mathrm{Al}-0.2 \mathrm{wt} \% \mathrm{Sc}$ alloy was cast, homogenised for $72 \mathrm{~h}$ at $620{ }^{\circ} \mathrm{C}$ and cold rolled $50 \%$. The rolled alloy was recrystallised for 30 minutes above the solvus temperature, at $620{ }^{\circ} \mathrm{C}$, giving a large grain size of $\sim 500 \mu \mathrm{m}$, using a fluidised bed to ensure a rapid heating rate and, hence, retain the scandium in solution. A precipitation treatment of $16 \mathrm{~h}$ at $400{ }^{\circ} \mathrm{C}$ was then used to develop a homogeneous dispersion of coherent $\mathrm{Al}_{3} \mathrm{Sc}$ dispersoids of $\sim 20 \mathrm{~nm}$ in diameter and with a spacing of $\sim 100 \mathrm{~nm}$ (see 3.1 below). Billets $15 \mathrm{~mm}$ in diameter and $100 \mathrm{~mm}$ long were machined from the alloy and deformed by ECAE, at room temperature, up to an effective strain of $\sim 10$ with no rotation of the billet between cycles (Route A). A circular cross section ECAE die was used, with a die angle of $120^{\circ}$ and a sharp die corner, giving a nominal Von Mises' effective strain of $\varepsilon_{\mathrm{vm}} \sim 0.7$ per pass. Full details of the ECAE press and deformation behaviour in the die can be found elsewhere [39].

The deformation structures of the billets were characterised at the centre of the ND-ED plane (normal and extrusion direction, i.e., the die symmetry plane) using EBSD, as a function of strain. For EBSD analysis the samples were mechanically polished followed by light electropolishing to give a strain-free surface. EBSD orientation maps were acquired from samples at different strain levels, using either a Philips XL30 FEG-SEM, or a Camscan Maxim FEG-SEM, both fitted with automated HKL-EBSD pattern collection systems with a spatial resolution of $\sim 50 \mathrm{~nm}$ and an angular resolution of $\sim 1^{\circ}$. EBSD data analysis was carried out using VMap, an in-house software package. In the data presented, HAGBs are defined as having misorientations greater than, or equal to, $15^{\circ}$ and low-angle boundaries (LABs) are defined as having misorientations of less than $15^{\circ}$. Generally, a minimum misorientation cut-off of $1.5^{\circ}$ has been used to eliminate excessive misorientation noise. In some of the detailed analysis of substructure at low strains, "Kuwahara filter" orientation averaging of adjacent pixels was used to reduce noise levels at low misorientations (improving the orientation resolution to $\sim 0.5^{\circ}$ ) allowing a minimum misorientation cut-off of $1^{\circ}$ [40]. Boundary misorientations are defined from the rotation angle of the angle axis pair that gives the minimum misorientation. TEM samples were prepared by conventional jet electropolishing and examined in a Philips CM20 TEM operating at $200 \mathrm{kV}$.

The results obtained were compared to previous work on a single-phase $\mathrm{Al}-0.13 \mathrm{wt} \% \mathrm{Mg}$ alloy [14-17], with a similar starting grain size and deformed under identical conditions. Additional low-strain data was obtained for the $\mathrm{Al}-0.13 \% \mathrm{Mg}$ alloy using the new Kuwahara filter method [40] to improve angular resolution. A homogenised DC casting, supplied by Alcan International, was cold rolled $50 \%$, recrystallised at $400{ }^{\circ} \mathrm{C}$ for 1 hour (to give a starting grain size of $\sim 500 \mu \mathrm{m}$ ), and identically deformed by ECAE. The substructural evolution of these samples was analysed in detail and compared to that in the dispersoid-containing $\mathrm{Al}-0.2 \mathrm{Sc}$ alloy. Both model alloys had low trace levels of $<0.001 \mathrm{Cu}, 0.002$ $\mathrm{Fe}$ and $0.003 \mathrm{Si}\left(\mathrm{wt}^{\mathrm{t}} \%\right)$.

\section{Results and discussion}

\subsection{Dispersoid distribution}

The $\mathrm{Al}_{3} \mathrm{Sc}$ dispersoids in the starting material, prior to ECAE deformation, are shown in a dark field TEM image in Fig. 1(a). The average dispersoid diameter was $\sim 20 \mathrm{~nm}$ and particle spacing was approximately $100 \mathrm{~nm}$. The spatial distribution of $\mathrm{Al}_{3} \mathrm{Sc}$ precipitates was found to be very homogeneous across a grain, as has been previously reported [41], due to the low level of partitioning of Sc during solidification. A corresponding $\langle 200\rangle$ SAD pattern is also shown in Fig 1(a), demonstrating the well-known coherency of the $\mathrm{Al}_{3} \mathrm{Sc}$ phase and their epitaxial orientation relationship with the matrix [41]. Fig. 1(b) shows a similar dark field TEM image after deformation by nine ECAE passes to a strain of $\varepsilon_{\mathrm{vm}} \sim 6$. As can be seen from Fig. 1, the dispersoid's size and distribution were found to be relatively unaltered after deformation. Due to their spacing, high strength, and the soft matrix, it is therefore evident that the $\mathrm{Al}_{3} \mathrm{Sc}$ precipitates are not sheared during high strain deforma- 

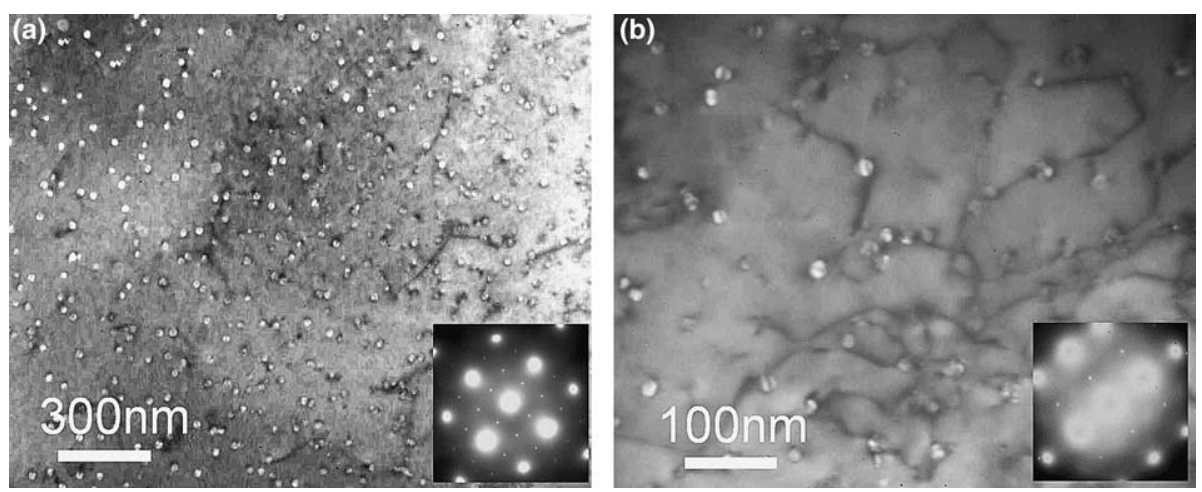

Fig. 1. Dark field TEM image and corresponding SAD pattern showing the distribution of $\mathrm{Al}_{3} \mathrm{Sc}$ dispersoids in $\mathrm{Al}-0.2 \mathrm{Sc}$ alloy; (a) prior to ECAE deformation and (b) after nine ECAE passes $\left(\varepsilon_{\mathrm{vm}} \sim 6\right)$. SAD patterns are shown as inserts.

tion. Gliding dislocations can by-pass small particles that intersect their slip plane by the Orowan mechanism, or by cross slip, which will develop Orowan, or prismatic, loops and this will greatly increase the dislocation density compared to in a single-phase alloy [25-27]. After ultra-high strain deformation such classical dislocation structures are not seen due to the very large numbers of dislocations that have interacted with the particles and the effects of recovery. However, compared to the single-phase alloy, a relatively high density of tangled dislocations was still visible within each grain/subgrain (Fig. 1(b); see also Figs. 5 and 8(b) below), which are pinned by the dispersoids. Dislocations are, therefore, trapped by the dispersoids even at ultra-high plastic strains significantly inhibiting recovery. In contrasts, in previous work on single-phase Al-alloys, it has been found that at similar high strains the cellular structures that develop contain very low densities of dislocations and most dislocations are adsorbed by the cell/ grain boundaries [17].

\subsection{Evolution of microstructural parameters}

To gain an overview of the comparative rates of grain refinement in the dispersoid-containing and single-phase alloys, the average boundary and orientation data obtained from several EBSD maps at each strain level are presented in Figs. 2 and 3. Due to the inhomogeneous nature of the deformation structures formed at low strains, with a large starting grain size, it is difficult to obtain reliable HAGB statistics for $\varepsilon_{\mathrm{vm}}<2$. Hence, data presented for samples at $\varepsilon_{\mathrm{vm}}<2$ should be regarded as having a significant degree of scatter. Fig. 2 shows the transverse HAGB spacing (grain width, or ND spacing) and percentage by area of HAGBs, as a function of strain for the Al-0.2Sc alloy, with equivalent data from the single-phase $\mathrm{Al}-0.13 \mathrm{Mg}$ alloy [15-17]. Statistical data averaged from several maps at the final strain reached of $\varepsilon_{\mathrm{vm}}=10$ is shown in Table 1 .

Fig. 2 indicates key differences in the grain refinement rate between the dispersoid-containing and single-phase

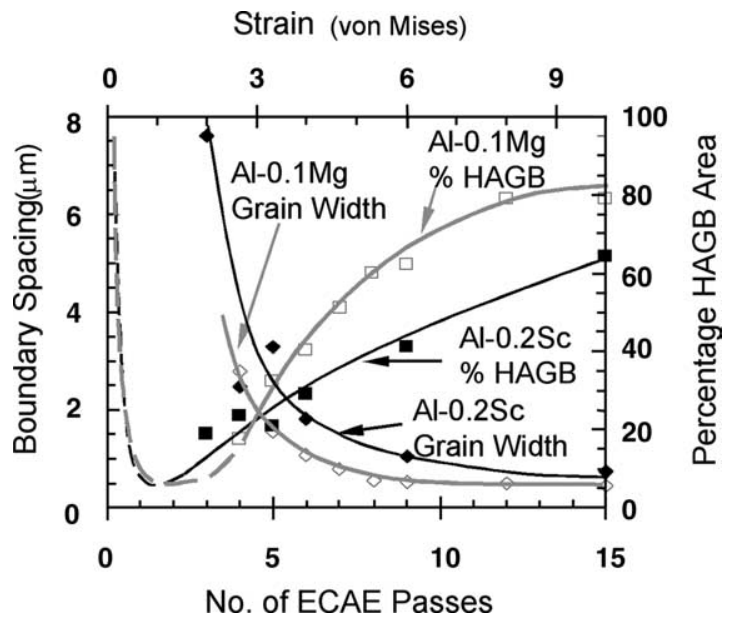

Fig. 2. EBSD statistical data showing the average transverse high angle grain boundary spacing and high angle grain boundary area fraction ( $\% \mathrm{HAGBs})$, as a function of strain, during ECAE processing of the Al-0.2Sc and single-phase $\mathrm{Al}-0.13 \mathrm{Mg}$ alloys, deformed under identical conditions.

alloys. At low to medium strains $\left(\varepsilon_{\mathrm{vm}}<2\right.$, Fig. 2$)$ the HAGB spacing reduces more quickly in the single-phase alloy. Although, with the scale shown, the two curves do eventually appear to nearly converge at very high strains, the average transverse HAGB spacing at a strain of $\varepsilon_{\mathrm{vm}}=10$ was still slightly greater in the $0.2 \mathrm{Sc}$ alloy (0.7 as opposed to $0.5 \mu \mathrm{m}$; see Table 1$)$. In addition, the dispersoid-containing $\mathrm{Al}-0.2 \mathrm{Sc}$ alloy has a significantly lower fraction of high-angle grain boundary area across the entire strain range, apart from at very low strains, where the data is noisy and the HAGBs present are largely from the initial grain structure and coarse deformation bands [15-17]. It should also be noted that at low strains the LAGB fraction in the EBSD data for the Al-0.2Sc alloy is affected by a lack of cell formation (see below 3.3), which would tend to increase the relative HAGB fraction. In Fig. 2 it is evident that there is a more gradual and linear increase in the percentage of HAGB area with strain in the Al-0.2Sc material, compared to the single-phase alloy, which does not reach 
(a) Strain (von Mises)

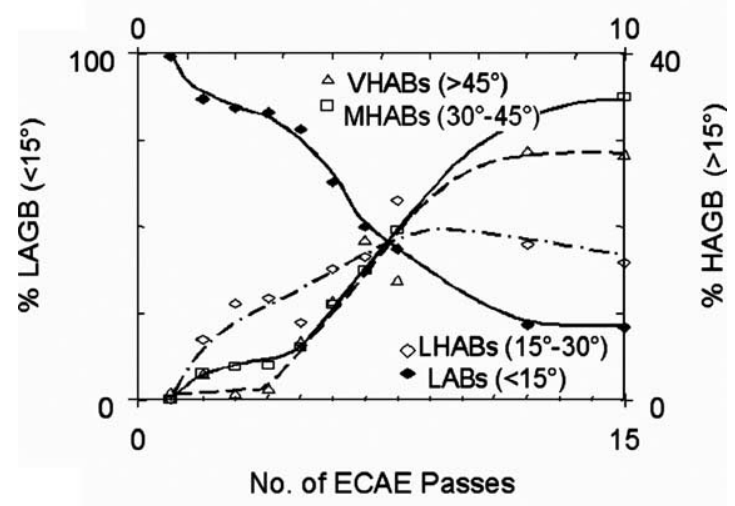

(b)

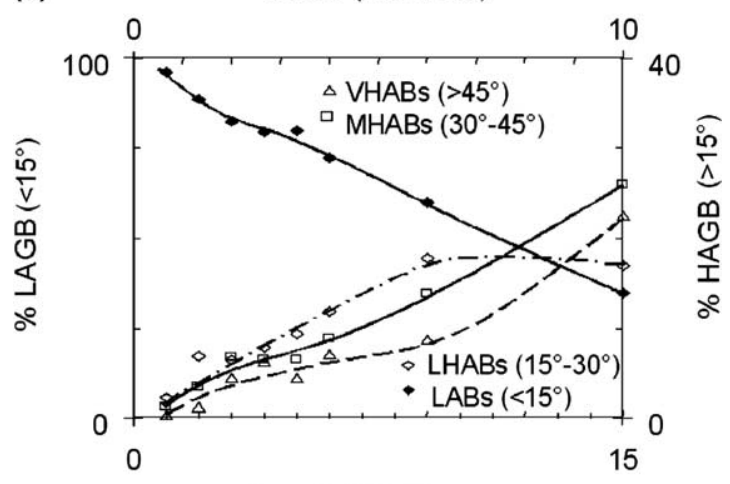

No. of ECAE Passes

Fig. 3. Comparison of the rates of development of boundary area fractions in four misorientation classes between (a) the $\mathrm{Al}-0.13 \mathrm{Mg}$ alloy and (b) the Al-0.2Sc alloy. The boundaries have been divided into $15^{\circ}$ misorientation ranges, giving; low angle boundaries (LAB), less than $15^{\circ}$, low high angle boundaries (LHAB), $15^{\circ}-30^{\circ}$, mediumhigh angle boundaries (MHAB), $30-45^{\circ}$, and very high angle boundaries (VHAB), with misorientations in excess of $45^{\circ}$. The low angle boundaries are plotted against the left vertical axis and all the high angle boundary classes against the right.

Table 1

Statistical EBSD data for the $\mathrm{Al}-0.2 \mathrm{Sc}$ and $\mathrm{Al}-0.13 \mathrm{Mg}$ alloys deformed by ECAE to a strain of 10 (15 ECAE passes)

\begin{tabular}{lcc}
\hline & Al-0.2Sc & Al-0.1 Mg \\
\hline Grain width (ND) $(\mu \mathrm{m})$ & 0.73 & 0.45 \\
Grain length (ED) $(\mu \mathrm{m})$ & 2.2 & 1.02 \\
Aspect ratio & 3.0 & 2.3 \\
Mean misorientation & 27 & 33 \\
$\%$ HAGB area & 64 & 79 \\
\hline
\end{tabular}

as high a maximum ( $64 \%$ compared to $78 \%$; Table 1$)$, or level-off towards a limiting value, within the strain range studied. In single phase alloys severely deformed by ECAE the fraction of HAGB area normally saturates at an upper limit of around $70-80 \%$, which is texture limited and is therefore affected by the deformation method $[5,15,16]$. This suggests that the rate of formation of new deformation-induced HAGB area is considerably retarded in the $\mathrm{Al}-\mathrm{Sc}$ alloy, due to the presence of the fine dispersoids, but may eventually saturate at the same level if the experiments had been continued to higher strains.

In Fig. 3(a) and (b), the boundary misorientations are divided into four coarse $15^{\circ}$ categories and plotted, as a function of strain, for the $\mathrm{Al}-0.13 \mathrm{Mg}$ and $\mathrm{Al}-0.2 \mathrm{Sc}$ alloys, respectively. In Fig. 3 LABs are defined as having misorientations of less than $15^{\circ}$, low-high angle (LHABs) $15^{\circ}$ to $30^{\circ}$, medium to high (MHABs) $30^{\circ}$ to $45^{\circ}$ and very high angle boundaries (VHABs) misorientations greater than $45^{\circ}$ (in Fig. 3 the LAB class is plotted against the left vertical axes and all the HAGB classes are plotted against the right). Although these divisions are arbitrary, the evolution of the fractions of the different boundary classes reveals useful information about the mechanisms of generation of new HAGBs. In the Al- $0.13 \mathrm{Mg}$ alloy the majority of new HAGBs formed at low strains are LHABs, in the range 15-30 (Fig. 3(a)), and these correspond to the appearance of microshear bands within the deformation structure and cell band/block boundaries that locally increase more rapidly in misorientation due to the presence of orientation gradients within unstable grains splitting into diverging orientations [11,15,16,24] (see below 3.3). Significant densities of Higher misorientation HAGBs (MHABs and VHABs) only appear, and then rapidly increase in fraction, after a strain of $2-3$. This is thought to be due to the increase in misorientation of the microshear bands and higher misorientation cell bands boundaries, which also increase in density with strain $[11,15,16]$.

In comparison, the high angle boundary classes in the Al-0.2Sc alloy were all observed to increase in fraction at a lower and more similar rate. This largely due to a lower rate of formation of $15-30^{\circ}$ misorientation boundaries at low strains and a reduced rate of MHABs and VHABs formation at medium to high strains. This might suggest that the higher misorientation cell band boundaries and microshear bands responsible for the majority of the new $15-30^{\circ}$ HAGBs in the single phase alloy at low strains are retarded by the presence of the dispersoids and this has a knock on effect on higher misorientation classes at higher strains; i.e., there is a smaller density of new HAGBs present able to increase their misorientation into the higher misorientation categories as the structure develops.

The effect of the lower rate of formation of new HAGBs in the dispersoid containing alloy on the final level of grain refinement found after severe deformation to a strain a high as ten is emphasised in Table 1, which shows EBSD statistics averaged from several maps obtained from the $\mathrm{Al}-0.1 \mathrm{Mg}$ and $\mathrm{Al}-0.2 \mathrm{Sc}$ alloys. Here, the average misorientations of all the boundaries in the single phase alloy are $33^{\circ}$, compared to $27^{\circ}$ in the dispersoid-containing material. The relative percentage of HAGB area is also significantly lower in the Al- 
$0.2 \mathrm{Sc}$ alloy deformed to this strain, being $64 \%$ compared to $79 \%$ in the single-phase alloy. More importantly, from the perspective of producing an ultra-fine grained material, the final grain structure is on average coarser, with significantly larger average HAGB spacings being observed in both the grain length and width.

In order to investigate in more detail the mechanisms responsible for the differences observed in the EBSD statistical data the microstructural development of the deformation structures with strain will be discussed below, using EBSD maps and TEM. In the EBSD maps "Kuwahara filter" orientation averaging [40] has been used to minimise misorientation noise. Low angle boundaries are shown in the figures above $1^{\circ}$ in misorientation as light grey lines. HAGBs are depicted as black.

\subsection{Substructural evolution at low strains}

\subsubsection{One ECAE pass $\left(\varepsilon_{v m} \sim 0.7\right)$}

Fig. 4 shows examples of a typical high-resolution EBSD maps of the Al-0.1Mg and Al-0.2Sc alloys after one ECAE pass, or $\varepsilon_{\mathrm{vm}} \sim 0.7$. The figures include representative relative boundary misorientation line scans across the maps. Fig. 4(a) shows that at a strain of $\varepsilon_{\mathrm{vm}} \sim 0.7$ a regular cell-band structure, similar to that seen in rolling at comparable strains (see Hurley and Humphreys [11]), has formed in the Al- $0.1 \mathrm{Mg}$ alloy. It should be noted that samples are not normally deformed in pure shear by ECAE and the strain path can contain other strain components (e.g., [39]), depending on the friction and die design. As the strain history is not as clearly defined as in rolling the deformation structures are more difficult to interpret, particularly after several ECAE passes. Nevertheless, after a single pass the main DDW direction and cell bands are aligned at approximately $60^{\circ}$ to the extrusion direction, which is theoretically the orientation of the principal shear plane within the ECAE die. In the example depicted, the grain is of an unstable crystallographic orientation and is also splitting into bands of alternating orientation approximately parallel to the extrusion direction. Line scan 2 in Fig. 4(a) indicates typical boundary misorientations of $3-4^{\circ}$ between the cell band boundaries. Higher misorientation cell boundaries are present between the alternating orientation bands parallel with the extrusion direction (see line scan 1) and some high angle boundary segments $\left(>15^{\circ}\right.$ misorientation) have already formed at their boarders intersecting the $60^{\circ}$ cell bands. In other more stable grains the primary feature of the deformation structure were $60^{\circ}$ aligned cell bands of $3-4^{\circ}$ misorientation. The incidental boundaries within the cell bands had very low misorientations $<2^{\circ}$.

In comparison, at low strains the deformation microstructure of the Al-0.2Sc alloy was significantly more heterogeneous than the single-phase alloy and can broadly be divided into two typical structures: (a)
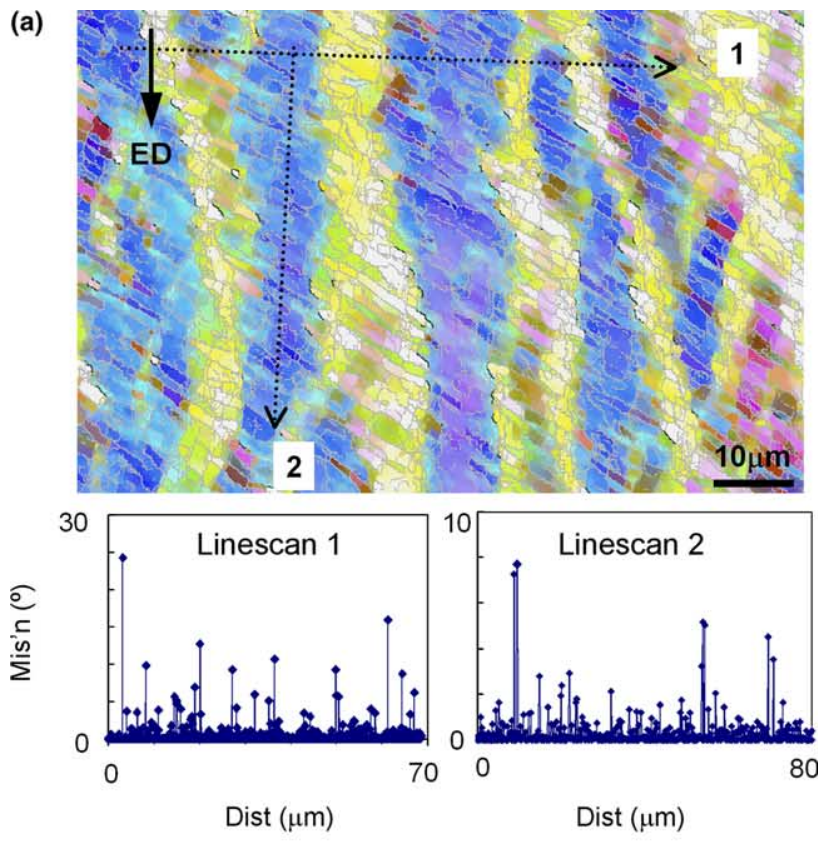

(b)
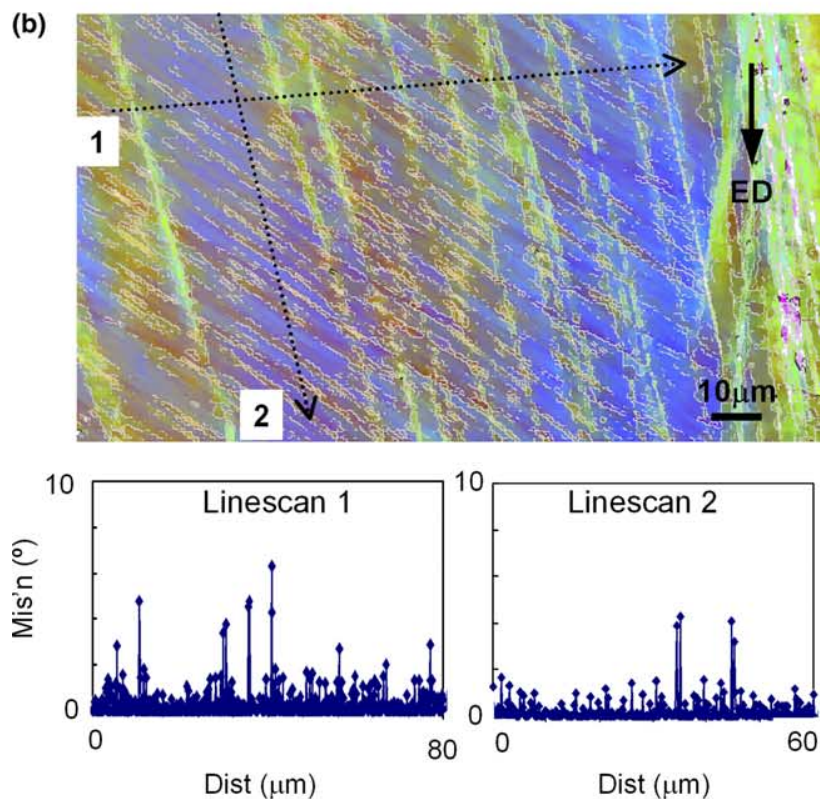

Fig. 4. High resolution, Kuwahara filtered, EBSD maps at a strain of $\sim 0.7$ (1 ECAE pass) showing; (a) a cell band substructure in the singlephase $\mathrm{Al}-0.1 \mathrm{Mg}$ alloy, and (b) diffuse, low-misorientation, linear boundaries, in a region away from coarse deformation bands in the Al-0.2Sc alloy. The line scans show typical relative boundary misorientations along the directions indicated.

(i) In stable grain orientations, a very low misorientation substructure was found to form after one ECAE pass $\left(\varepsilon_{\mathrm{vm}} \sim 0.7\right)$. This structure is illustrated in Fig. 4(b) and consists of a set of very straight and parallel boundaries of low $1-2^{\circ}$ misorientation, aligned $\sim 60^{\circ}$ to the extrusion direction, intersected by a second set of parallel boundaries aligned at $\sim 15^{\circ}$ to the extrusion direction. The $60^{\circ}$ aligned boundaries are diffuse less developed versions of 
the more defined cell-band boundaries seen in the single phase alloy, which had higher misorientations at the same strain. Representative example line-scans shown in Fig. 4(a) confirm the typically low misorientations in this structure. No incidental cell boundaries were seen within the linear boundaries, which were observed between the DDWs defining the cell bands in the single phase alloy. A similar type of structure, although with slightly higher misorientations, remained generally visible after three ECAE passes (Fig. 7(b)) and in some local stable regions after as many as five ECAE passes (Fig. 9).

(ii) Grains that were unstable due to their crystallographic orientation, or neighbouring constraint, were found to divide into coarse deformation bands and produce HAGBs at their borders with typical spacings of $\sim 10-20 \mu \mathrm{m}$. Within many of these deformation bands, little organised substructure was observed, although large orientation gradients suggested the presence of a high dislocation density. This type of structure is illustrated after three ECAE passes in the following section (Fig. 7(a)).

The dislocation structures present in the single-phase and dispersoid-containing alloys, after one ECAE pass, are shown in TEM micrographs in Fig. 5. As expected from Fig. 4(a), a well-defined cell band structure has formed in the Al-0.1Mg alloy (Fig. 5(a)), with relatively clean cell boundaries and most subgrains/cells contain a very low density of free dislocations. In contrast, the TEM micrograph of the Al-0.2Sc alloy (Fig. 5(b)) shows little sign of an organised cell structure and has a high density of dislocations pinned by the $\mathrm{Al}_{3} \mathrm{Sc}$ dispersoids. These observations agree with reports that cell formation is delayed in dispersion strengthened alloys with inter-particle spacings finer than the matrix natural cell size [32,33]. Diffuse linear dislocation walls can be observed similar to those seen in the EBSD maps (Fig. 4(b)), but they are not fully condensed and can still be seen to be comprised of individual dislocations.

\subsubsection{Three ECAE passes $\left(\varepsilon_{v m} \sim 2\right)$}

Figs. 6 and 7 show high-resolution EBSD maps illustrating the typical types of structures observed after three ECAE passes in the $\mathrm{Al}-0.13 \mathrm{Mg}$ and $\mathrm{Al}-0.2 \mathrm{Sc}$ alloys, respectively. Again, representative line-scans have been used to illustrate typical boundary misorientations. In Fig. 6 the well-defined banded cellular substructure, observed after the first ECAE pass, is still present in the single-phase alloy, and "Line scan 2" shows that the boundary misorientation of the cell bands within regions of uniform deformations have remained at only $4-6^{\circ}$. Although the deformation structure is not as distinct as in the examples shown by Hurley and Humphreys during rolling [11], due to the less well defined deformation during ECAE processing, features typical of microshear bands can now be seen cutting through the cell bands at approximately $60^{\circ}$ to the extrusion direction, which are 'kinked' and re-aligned in the process (see Hurley and Humphreys, Fig. 4(a), for comparison [11]). "Line scan 1" confirms that lattice rotation within these microshear bands generates high misorientations across their boundaries. Such boundaries provide a major source of new high-angle boundaries during deformation of the single-phase alloy. It also appears that the microshear bands tend to form at $60^{\circ}$ to the extrusion direction, approximately parallel with the die shear plane. It should be noted that the original cell band structure has also now started to rotate away from the shear plane towards the extrusion direction. In principal these boundaries will be misaligned with the die shear plane when the billet is replaced in the die each cycle, by $60^{\circ}$, but at low strains when they have low
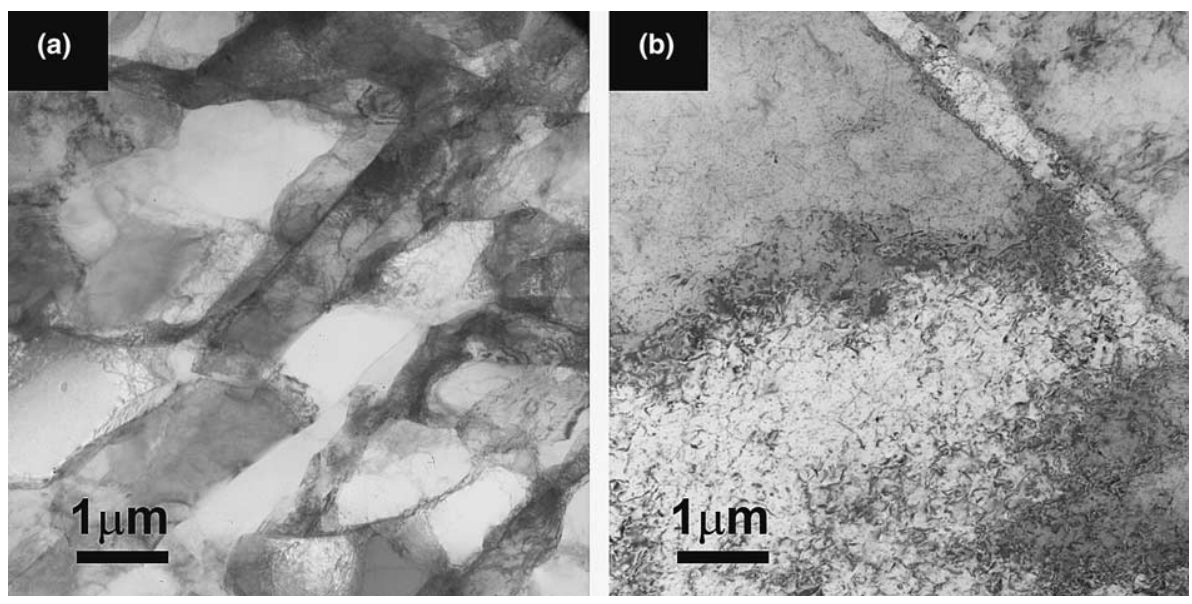

Fig. 5. TEM micrographs after one ECAE pass showing (a) the formation of a regular banded well defined cell structure in the Al-0.1Mg alloy and (b) the absence of a cell structure in the Al-0.2Sc alloy, which primarily contains dislocation tangles and diffuse linear dislocation walls. 


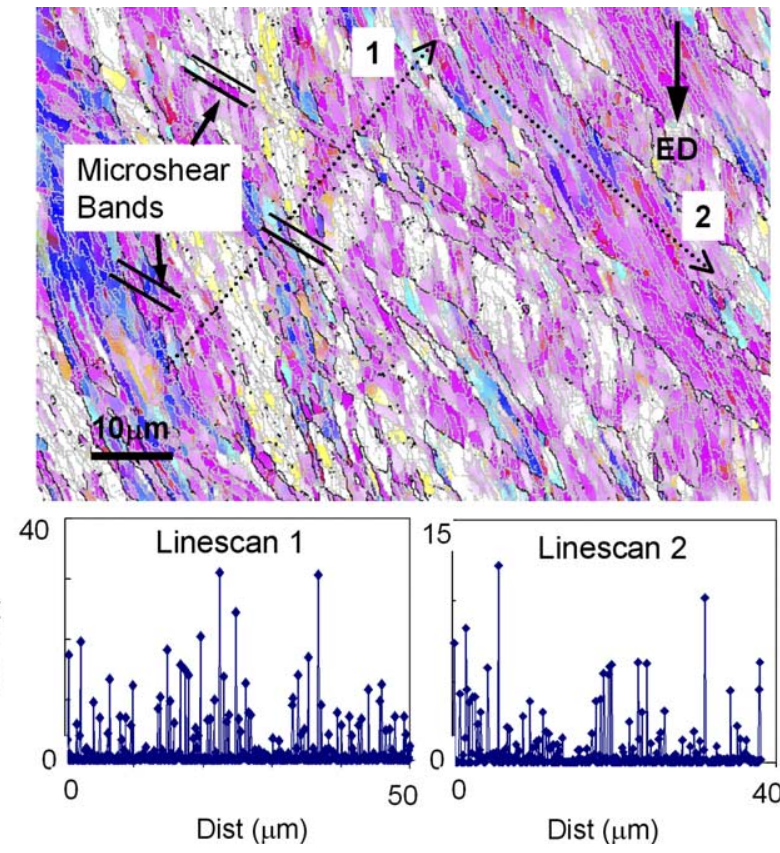

Fig. 6. High resolution EBSD map showing the development of the deformation structure in the $\mathrm{Al}-0.13 \mathrm{Mg}$ alloy after a strain of 2 (three ECAE passes), including line scans showing typical relative boundary misorientations along the directions indicated.

misorientations and are transient in nature, can readjust their orientation to become realigned with the macroscopic shear plane during each cycle. If certain cell band/block boundaries develop high enough misorientations to become permanent, typically within unstable grains, they will then rotate towards the extrusion direction. Lamellar boundary structures promote instability to shear perpendicular to the boundaries [42], which triggers the formation of microshear bands, if they become misaligned with the dies shear plane. The microshear bands have high misorientations and are permanent features of the deformation structure [11]. Once formed, they undergo a rigid-body rotation towards the extrusion direction on subsequent cycles and their spacing is compressed $[10,16]$. This process is eventually responsible for the formation of lamellar boundary structures and the elongated "ribbon grains" observed at high strains [15-17]. However, at intermediate strains it causes a complex microstructure to develop by subsequent microshear bands kinking the rotated permanent cell band/block boundaries and earlier microshear bands.

Fig. 7 illustrates typical deformation structures present in the Al-0.2Sc alloy after three ECAE passes $\left(\varepsilon_{\mathrm{vm}} \sim 2\right)$. Fig. 7(a) shows a region of unstable orientation, containing highly misorientated deformation bands separated by HAGBs with a spacing of $\sim 10$ $\mu \mathrm{m}$. Representative line scans, also shown in Fig. 7(a), confirm that the deformation band boundaries are of very high misorientation (up to $60^{\circ}$ in the case illus- (a)
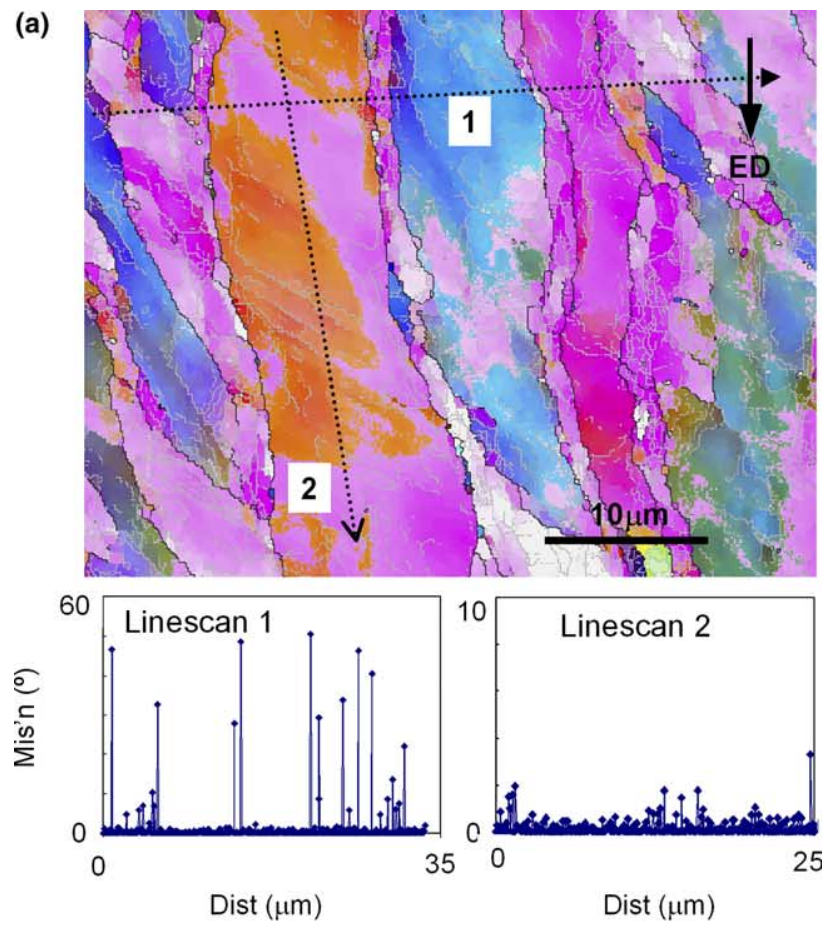

(b)
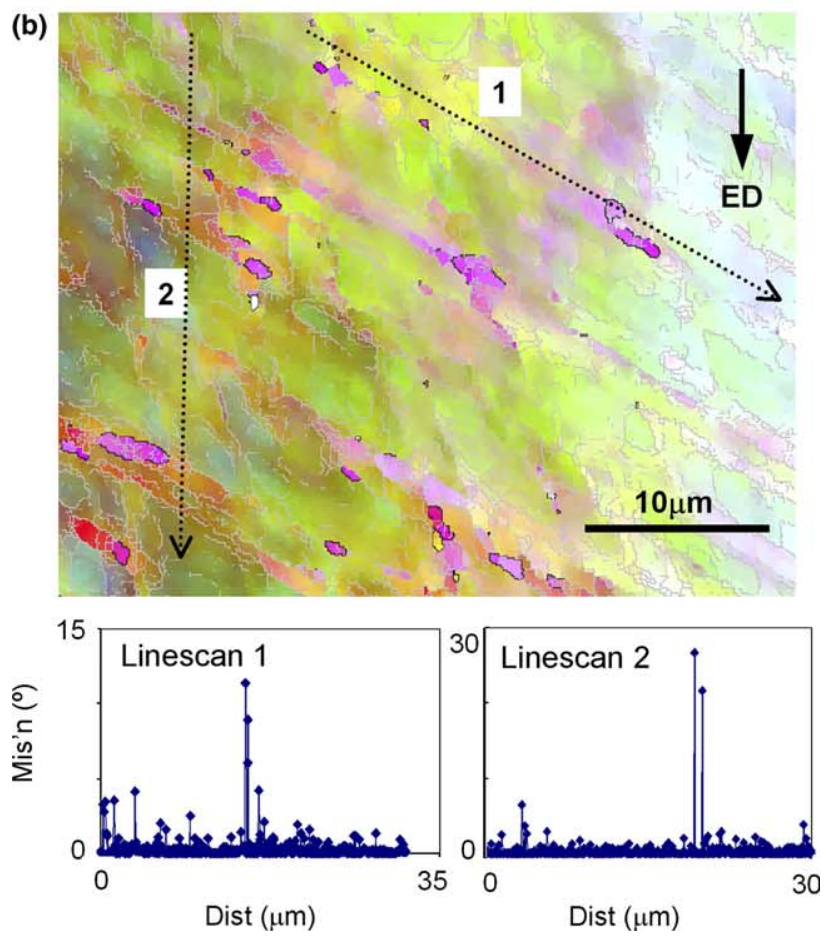

Fig. 7. High resolution EBSD maps showing typical features of the microstructure of the $\mathrm{Al}-0.2 \mathrm{Sc}$ alloy after deformation to a strain of $\sim 2$ (three ECAE passes): (a) a region of coarse deformation banding showing highly misorientated deformation band boundaries and an illdefined low misorientation substructure and (b) a stable region of diffuse substructure, similar to that in Fig. 6 after one ECAE pass.

trated), and that little regular substructure is present within the bands. In comparison, Fig. 7(b) shows a stable region away from any coarse deformation bands. The deformation structure is similar to that in 
Fig. 4(b), after one ECAE pass, although the misorientation of the dislocation boundaries has increased slightly. However, the boundaries are still not sharply defined (cf. Fig. 6) and significant orientation gradients exist, suggesting many of the boundaries are still diffuse dislocation walls. It is therefore clear from Fig. 7 that, as well as developing more weakly misorientated dense dislocation walls, that define the cell bands in the ingle phase alloy, intense microshear bands do not form in the Al-0.2Sc alloy at this strain level and, hence, a mechanism that is a major source of new high misorientation boundaries at low to medium strains in single phase alloys is suppressed by the presence of the dispersoids.

The EBSD maps suggest that a regular cell structure has still not formed in the Al-0.2Sc alloy by a strain of $\varepsilon_{\mathrm{vm}} \sim 2$. This was confirmed by TEM. In Fig. 8(a) a welldefined cell structure can be seen in the $\mathrm{Al}-0.1 \mathrm{Mg}$ alloy with significant regions containing a low dislocation density in the cell interiors and sharp, clean, cell bound- aries. In contrast, the Al-0.2Sc alloy (Fig. 8(b)) still contains a high density of free dislocations and, although some boundaries are visible, they correspond to the linear features seen in the EBSD map and are diffuse and of low misorientation.

\subsection{Microstructural evolution to ultra-high strains}

Fig. 9 shows an EBSD map of the Al-0.2Sc alloy after five ECAE passes $\left(\varepsilon_{\mathrm{vm}} \sim 3.3\right)$. In previous work on the single-phase alloy [17], the deformation structures at this strain level were found to consist of lamellar boundaries, of $\sim 5 \mu \mathrm{m}$ in width, rotated towards the extrusion direction $\left(\sim 15^{\circ}\right.$ from ED), containing equiaxed subgrains of $\sim 0.7 \mu \mathrm{m}$ in size. In contrast, Fig. 9 shows a much lower density of HAGBs, which are heterogeneously distributed, and a finely spaced lamellar boundary structure has yet to form, although most of the well defined HAGBs present are now aligned and
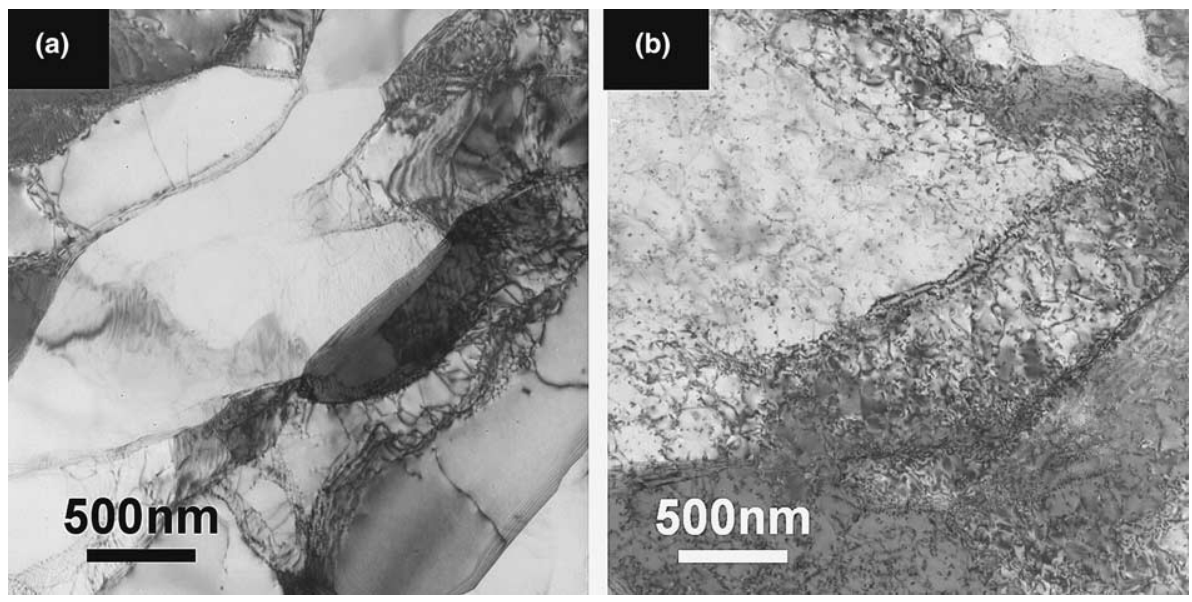

Fig. 8. TEM micrographs showing; (a) a well-defined cell structure with regions of low dislocation density in the cell interiors in the Al-0.13Mg alloy after three ECAE passes and (b) a high dislocation density, with some diffuse boundaries, in the Al-0.2Sc alloy at the same strain.

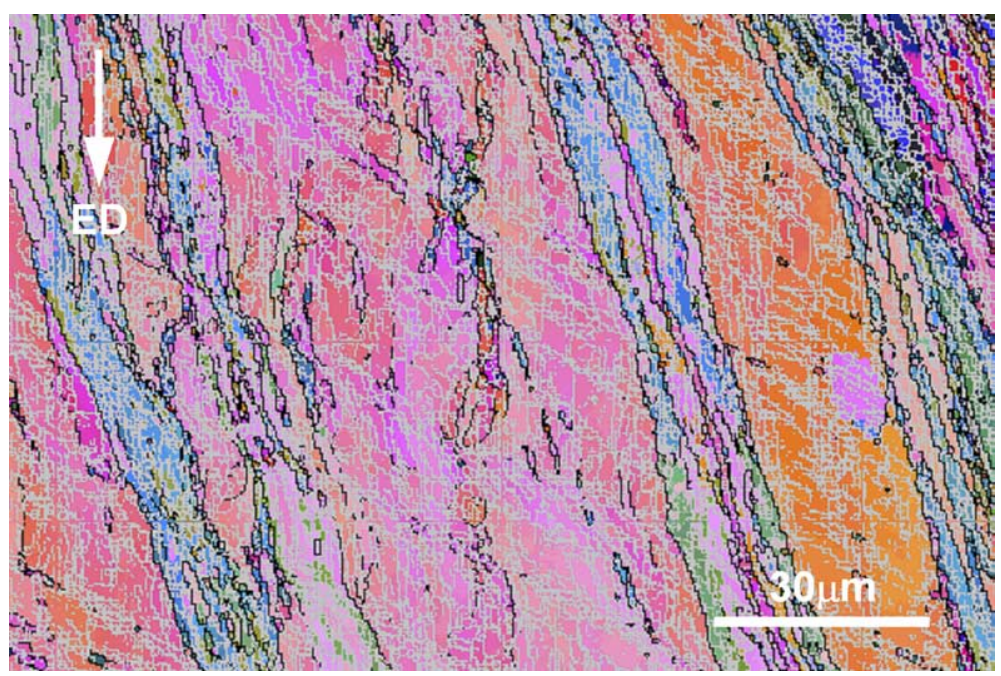

Fig. 9. EBSD map (step size $0.35 \mu \mathrm{m}$ ) showing the deformation structure produced in the Al-0.2Sc alloy after five ECAE passes $\left(\varepsilon_{\mathrm{vm}} \sim 3.3\right.$ ). 
have the same angle with the extrusion direction. The low density of these boundaries and their spacing is consistent with them virtually all being produced by rotation and compression of the original grain and coarse primary deformation band boundaries seen at lower strains. Within these aligned boundaries two sets of diffuse boundaries still persist, aligned similarly to that seen at low strains; i.e., $60^{\circ}$ to ED and close to parallel with ED. As they have not rotated away from the shear plane these boundaries are probably still transient features, and have relatively low misorientations $<5^{\circ}$.

When the strain is increased further, in the singlephase alloy the lamellar boundary spacing reaches the subgrain size at a strain of $\varepsilon_{\mathrm{vm}} \sim 6$ (Fig. 10(a)), forming long thin ribbon grains. In comparison, in the dispersoid containing alloy, due to the lower rate of new HAGB formation at low strains, the transverse HAGB spacing in ND is on average considerably wider (Fig. 10(b)), although a lamellar boundary structure is emerging. The transient, regular, linear boundaries seen at lower strains (Fig. 9) have also now been replaced by irregular subgrains. Ultra-fine grains can be seen starting to form in bands where the HAGBs originally formed at the periphery of deformation bands have locally converged with the subgrain size.

At the highest strain level investigated $\left(\varepsilon_{\mathrm{vm}} \sim 10,15\right.$ ECAE passes), in the dispersoid-containing alloy, the ultra-fine grain regions were found to have increased and cover approximately $80 \%$ of the microstructure (Fig. 11b). However, some large unrefined fibrous grains were retained within the deformation structure, so that on average the grain size was coarser and there was a greater percentage of LAGBs than in the single-phase alloy (Table 1). In comparison, the single-phase alloy deformed to the same strain had a higher fraction of ultra-fine grains (Fig. 11(a)) [15-17]. Although it also still contained some larger grain fragments, they were not as coarse as those seen in the dispersoid-containing alloy. These retained fibrous grains probably correspond to more stable orientations that survive to high plastic strains without subdivision. Similar grain fragments are found at lower strains in the single phase alloy,
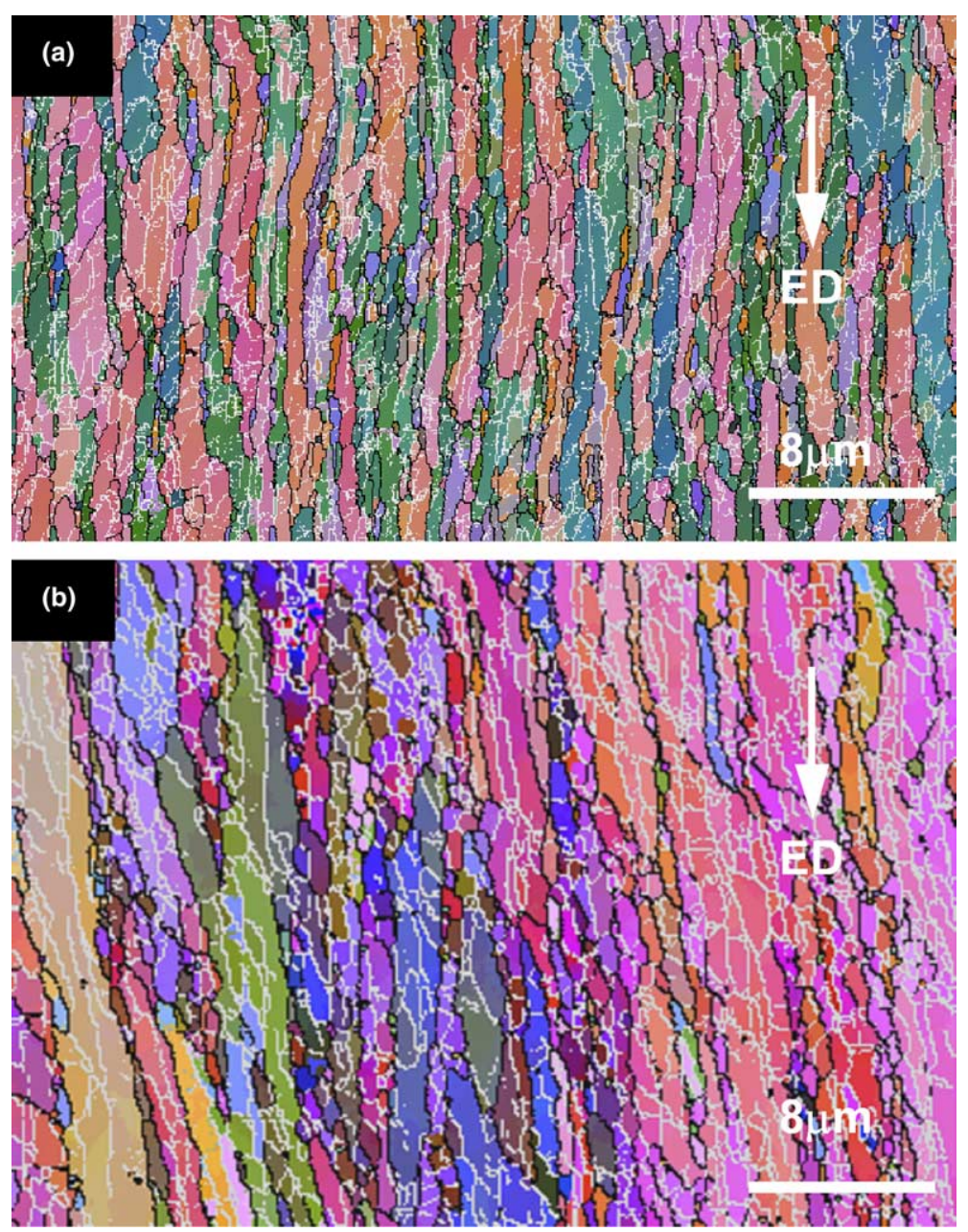

Fig. 10. EBSD maps showing typical deformation structures; in (a) the single phase $\mathrm{Al}-0.13 \mathrm{Mg}$ alloy and (b) the $\mathrm{Al}-0.2 \mathrm{Sc}$ alloy after deformation by eight ECAE passes $\left(\varepsilon_{\mathrm{vm}} \sim 5\right)$ and nine ECAE passes $\left(\varepsilon_{\mathrm{vm}} \sim 6\right)$, respectively. The map in (a) is reproduced from [17]. 

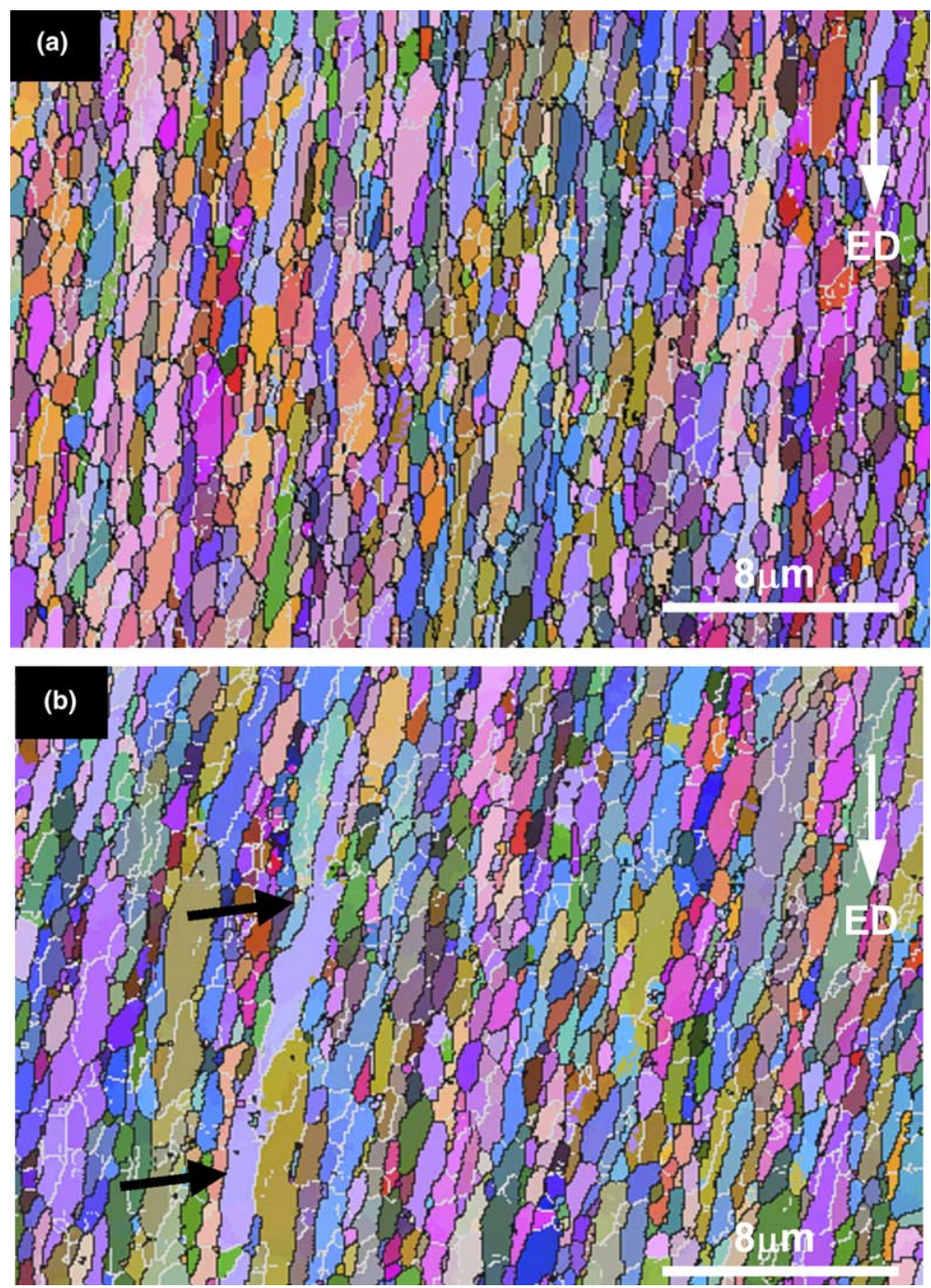

Fig. 11. EBSD maps showing ultra-high strain microstructures; in (a) the single phase Al-0.13Mg alloy and (b) the Al-0.2Sc alloy after deformation to a strain of $\varepsilon_{\mathrm{vm}} \sim 10$ (15 ECAE passes). Large retained unrefined fibrous grains are arrowed. The map in (a) is reproduced from [24].

and reflect the retarded rate of grain subdivision in the $\mathrm{Al}-\mathrm{Sc}$ alloy. If the dispersoid containing material was deformed to higher strains their microstructures would be expected to become more similar.

\subsection{The effect of dispersoids on the microstructure evolution}

The rate of dislocation generation by dispersoids $\left(\rho_{\mathrm{d}}\right)$, relative to that in a single-phase alloy $\left(\rho_{\mathrm{s}}\right)$, with strain can be estimated by comparing Ashby's geometrically necessary dislocation density, for a non-deformable inclusion $\left(\rho_{\mathrm{d}}=3 f_{\mathrm{v}} \gamma / r b\right.$ [26]), to that required by shear of the matrix with a given slip line length $\left(\gamma=b \rho_{\mathrm{s}} L\right.$ [43]);

$\frac{\rho_{\mathrm{d}}}{\rho_{\mathrm{s}}}=\frac{3 f_{\mathrm{v}} L}{r}$

where $f_{\mathrm{v}}$ and $r$ are the dispersoid volume fraction and radius and $L$ is the slip-line length in the single-phase al- loy. At low strains, if $L$ is approximately the width of a granular scale deformation band $(\sim 20 \mu \mathrm{m}) f_{\mathrm{v}} \sim 0.004$ [17] and $r=10 \mathrm{~nm}$, Eq. (1) gives approximately an order of magnitude increase in dislocation density. If these dislocations recovered to form cells it might, therefore, be expected that the average cell boundary misorientation would increase more rapidly with strain in the dispersoid-containing alloy. However, the generation of dislocations alone does not simply translate to an increase in HAGB area, which is more dependent on the mechanisms of grain subdivision by the formation of coarser scale microstructural features. Incidental cell boundaries do not increase in misorientation greatly above $3^{\circ}$, even at extremely high strain levels $[10,11,16,17]$. Whereas the formation of a submicron grain structure predominantly occurs due to the convergence of more coarsely spaced deformation induced HAGBs, that are generated heterogeneously, and reduce in spacing with strain until their separation approaches the subgrain size $[15,16]$. 
In a single-phase Al-alloy, with low solute levels, it has previously been shown that grain subdivision occurs on up to four length scales [15-17]. If the alloy has a large starting grain size coarse granular scale deformation bands are formed in unstable grains that rapidly rotate to diverging orientations. On a finer scale, volumes within the deformation bands, and stable grains form transient cell bands (Hurley and Humphreys [11]), or a cell block structure (Risø terminology [7-9]) at low strains, within which dislocations recover to form incidental cell boundaries. These cell bands are then intersected by microshear bands as the strain increases [11]. Of these subdivision processes, it has been shown that the formation of granular scale deformation bands and microshear bands can readily produce new HAGBs. Some cell band boundaries also evolve into permanent boundaries that can increase in misorientation at high strains, particularly where a grain becomes unstable as it rotates [11].

In the Al-Sc alloy it is apparent that two levels of grain subdivison are strongly repressed, to the point at which they hardly occur, due to the presence of the dispersoids. At the finest scale, the strong inhibition of recovery prevents the formation of a cell structure, at least until much higher strains where subgrains are eventually seen. However, these are probably formed by rearrangement of dense dislocation walls during the compression of the HAGBs to form a lamellar structure, rather than from the recovery of incidental cell boundaries. Aligned linear dislocation walls do develop parallel to the plains of main slip activity, similar to DDWs that define the cell bands in a single phase alloy, but they are much more diffuse and have lower misorientations due to the inhibition of recovery and slip homogenisation. This allows less possibility for them to become permanent boundaries that then increase in misorientation with strain. The intense microshear bands seen in the single-phase alloy at low to medium strains are also not observed to form, and these two factors probably have the greatest effect on inhibiting grain refinement in the Al-Sc alloy. Microshear bands are repressed because dispersoids help to homogenise slip and inhibit the formation of a well-defined cell band structure, comprised of a lamellar of sharp DDWs, and are, hence, less likely to cause the instability required to stimulate intense microshear bands [42]. Many of the cell band/ block boundaries in the single-phase alloy appear to reach a sufficiently high misorientation to become permanent at higher strains and reorientate towards the shear direction, while the diffuse boundaries in the dispersoid-containing alloy stay as transient features to much higher strains (Fig. 9) and do not appear to act as a major source of new HAGBs because of their generally lower misorientations. The main source of new HAGB area in the dispersoid containing alloy at low to medium strains is therefore largely restricted to the formation of coarse grain-scale deformation bands, which occurs at relatively low strains, and the extension of these, and the original grain boundaries caused by their geometrical shape change with strain.

Due to the much lower rate of generation of new HAGBs in the Al-Sc alloy, at low to medium strains, the formation of a lamellar grain structure is delayed relative to the single-phase alloy. Thus at higher strains of $\varepsilon_{\mathrm{vm}} \sim 6$, when the lamellar boundary spacing converges with the subgrain size and a ribbon grain structure is already seen in the single-phase alloy, in the dispersiod containing material lamellar HAGBs have only started to converge with the subgrains in local bands of higher HAGB density originating in unstable grain orientations. Ultimately, at ultra-high strains the deformation structures of the two materials become more similar. However, the inhibition of the main mechanisms of new HAGB formation at lower strains in the Al-Sc alloy leads to larger unrefined grain fragments (corresponding to more stable grain orientations) being retained to higher strains than in the single phase alloy. Thus, the deformation structure developed by a strain of $\varepsilon_{\mathrm{vm}}=10$ in the Al-Sc alloy is more reminiscent of that seen in the single phase alloy at a strain of $\varepsilon_{\mathrm{vm}}=8$, and does not contain such a high fraction of ultra-fine grains.

A further factor that may affect the behaviour of the two alloys is the development of different textures. This has not yet been studied. However, the presence of a strong deformation texture will tend to result in a statistically higher fraction of LAGBs in a heavily deformed alloy and thus a coarser ultra-fine grain size after severe deformation [44]. In ECAE processing alloys develop shear textures, which are relatively weak compared to those seen in rolling [45]. Although at lower strains, in rolled materials, there is some evidence that nondeformable particles may sharpen the deformation texture by homogenising slip, small volume fractions of particles have not been found to have a large influence on texture development $[37,38]$ and this effect is therefore not considered to be important.

The above discussion will of course be dependent on the interparticle spacing, which is exceptionally fine in Al-Sc alloys $(100 \mathrm{~nm})$, and the influence of the dispersoids would be expected to reduce as their density decreases.

\section{Conclusions}

The microstructural evolution and grain refinement mechanisms have been compared in a single-phase Al$0.13 \mathrm{Mg}$ and an $\mathrm{Al}-0.2 \mathrm{Sc}$ alloy containing fine dispersoids during severe deformation by ECAE processing. The rate of grain refinement was considerably reduced in the dispersoid-containing alloy, which lead to a signif- 
icantly less refined submicron grained microstructure at the highest strain investigated $\left(\varepsilon_{\mathrm{vm}}=10\right)$.

High resolution EBSD has been used to confirm that in a single-phase $\mathrm{Al}-0.13 \mathrm{Mg}$ alloy, the high misorientation boundaries introduced by microshear bands, and at cell block boundaries in unstable grains at low strain $\left(\varepsilon_{\mathrm{vm}}<3\right)$, make an important contribution towards the formation of an ultra-fine grain structure at high strains. The presence of a high-density of non-shearble dispersoids inhibits both the formation of cells and the DDWs, which define the cell band structures seen at low to moderate strains in single-phase alloys. The more weakly misorientated and diffuse boundaries present in the dispersoid-containing alloy, plus the homogenisation of slip, prevents the formation of intense microshear bands, which blocks this important mechanism of HAGB formation. This in turn delays the formation of a lamellar HAGB structure and the development of a uniform submicron grained material at ultra-high strains.

The lower rate of new HAGB generation in alloys containing fine dispersoids has significant consequences for developing thermally stable ultra-fine grained alloys by severe deformation.

\section{Acknowledgement}

The authors would like to acknowledge the support of the EPSRC (grant GR/L96779) and are grateful to Dr. Jacob Bowen for permission to reproduce his Al$0.13 \mathrm{Mg}$ alloy results.

\section{References}

[1] Hayes JS, Kyte R, Prangnell PB. Mat Sci Technol 2000;16:1259.

[2] Valiev RZ. In: Lowe TC, Valiev RZ, editors. Investigations and applications of severe plastic deformation. NATO Science Series 3, 80. Netherlands: Kluwer Academic Publishers; 2000. p. 221.

[3] Segal VM, Reznikov VI, Drobyshevskiy AE, Kopylov VI. Russ Metal 1981;1:99.

[4] Gholinia A, Bowen JR, Prangnell PB, Humphreys FJ. In: Sato T, Kumai S, Kobayashi T, Murakami Y, editors. 6th International Conferernce on Aluminium Alloys (ICAA-6), 1. Toyohasi, Japan: JILM publishers; 1998. p. 577.

[5] Heason CP, Prangnell PB. Mat Sci Forum 2002;408-412:733.

[6] Komura S, Berbon PB, Utsunomiya A, Furukawa M, Horita Z, Nemto M, et al. In: Bieler TR, Lalli LA, MacEwen SR, editors. Hot deformation of Al-alloys II. USA: TMS Publishers; 1998. p. 125.

[7] Bay B, Hansen N, Hughes DA, Kuhlmann-Wilsdorf D. Acta Metall Mater 1992;40:205.

[8] Bay B, Hansen N, Kuhlmann-Wilsdorf D. Mater Sci Eng 1992;A158:139.
[9] Hughes DA, Hansen N. Acta Mater 1997;45:3871.

[10] Hughes DA, Hansen N. Acta Mater 2000;48:2985.

[11] Hurley PJ, Humphreys FJ. Acta Mater 2003;51:1087.

[12] Hurley PJ, Bate PS, Humphreys FJ. Acta Mater 2003;51:4737.

[13] Humphreys FJ, Prangnell PB, Bowen JR, Gholinia A, Harris C. Philos Trans R Soc Lond 1999;A357:1663.

[14] Bowen JR, Prangnell PB, Humphreys FJ. Mat Sci Technol 2000;16:1246.

[15] Prangnell PB, Bowen JR, Gholinia A. In: Dinesen AR, et al., editors. 22nd Risø International Symposium on Materials Science, Science of Metastable and Nanocrystalline Alloys. Denmark: Roskilde; 2001. p. 105.

[16] Prangnell PB, Bowen JR. In: Zhu YT, et al, editors. Second International Symposium on Ultra-Fine Grained Materials. Seattle: TMS; 2002. p. 89.

[17] Bowen JR. The formation of ultra-fine grained model aluminium and steel alloys; PhD thesis, UMIST, UK; 2000.

[18] Hutchinson B. Philos Trans R Soc Lond 1999;357A:1471.

[19] Prangnell PB, Hayes JS, Bowen JR, Apps PJ, Bate PS. Acta Mater 2004;52:3193.

[20] Humphreys FJ, Ardakani MG. Acta Metal Mater 1994;42:749.

[21] Humphrey FJ. Acta Metall 1979;27:1801.

[22] Jazeri H, Humphreys FJ. In: Gottstein G, Molodov DA, editors. 5th International Conference on Recrystallization and Related Annealing Phenomena. Belgium: Achen; 2001. p. 549.

[23] Apps PJ, Bowen JR, Prangnell PB. In; Zehetbauer M, Valiev RZ, Editors. Nanomaterials by Severe Plastic Deformation-NANSPD2, Vienna Austria, December, 2002; p. 138.

[24] Apps PJ, Bowen JR, Prangnell PB. Acta Mater 2003;51:2811.

[25] Humphreys FJ. In: Loretto MH, editor. Dislocations and properties of real materials. London: IOM; 1984. p. 175.

[26] Hirsch PB, Humphreys FJ. In: Argon AS, editor. Physics of strength and plasticity. MIT Press; 1969. p. 189.

[27] Ashby MF. Philos Mag 1970;21:399.

[28] Humphreys FJ, Hirsch PB. Philos Mag 1976;34:373.

[29] Barlow CY, Hansen N, Liu YL. Acta Mater 2002;50:171.

[30] Martin JW. Precipitation hardening. 2nd ed. Oxford: Butterworth Heinemann; 1998. p. 127.

[31] Humphreys FJ, Hatherly M. Recrystallization and annealing phenomena. Oxford: Pergamon; 2004.

[32] Lewis MH, Martin JW. Acta Metall 1963;11:1207.

[33] Brimhall JL, Klein MJ, Huggins RA. Acta Metall 1996;14:459.

[34] Gudmundsson H, Brooks D, Wert JA. Acta Metall Mater 1991;39:19.

[35] Lloyd DJ, Kenny D. Acta Metall 1980;28:639.

[36] Habiby F, Humphreys FJ. Text Microstruct 1993;20:125.

[37] Engler O, Hrisch J, Lücke K. Acta Mater 1989;37:2743.

[38] Juul Jensen D, Hansen N, Humphreys FJ. In: Kallen JS, Gottstein G, editors. ICOTOM8. New Medici: TMS; 1987. p. 431.

[39] Bowen JR, Gholinia A, Roberts SM, Prangnell PB. Mat Sci Eng 2000;A287:87.

[40] Hurley PJ, Humphreys FJ. J Microsc 2002;205:218.

[41] Costello FA, Robson JD, Prangnell PB. Mat Sci Forum 2002;396-402:757.

[42] Rauch EF. Solid State Phenom 1992;23-24:317.

[43] Hull D, Bacon DJ. Introduction to dislocations. 3rd ed.. Oxford: Pergamon Press; 1992. p. 69.

[44] Heason CP, Prangnell PB. In: Zhu YT, Langdon TG, Valiev RZ, Semiatin SL, Shin DH, Lowe TC, editors. Ultrafine grained materials III. TMS; 2004. p. 111.

[45] Gholinia A, Bate PS, Prangnell PB. Acta Mater 2002;50:2121. 